\title{
Affective responses to sweet products and sweet solution in British and Finnish adults
}

\section{Tuorila, Hely}

2017

Tuorila , H, Keskitalo-Vuokko , K, Perola , M , Spector, T \& Kaprio , J 2017 , ' Affective responses to sweet products and sweet solution in British and Finnish adults ' , Food Quality and Preference, vol. 62 , pp. 128-136 . https://doi.org/10.1016/j.foodqual.2017.06.021

http://hdl.handle.net/10138/309040

https://doi.org/10.1016/j.foodqual.2017.06.021

cc_by_nc_nd

acceptedVersion

Downloaded from Helda, University of Helsinki institutional repository.

This is an electronic reprint of the original article.

This reprint may differ from the original in pagination and typographic detail.

Please cite the original version. 
2 Tuorila H, Keskitalo-Vuokko K, Perola M, Spector T, Kaprio J. Affective responses to to sweet products and 3 sweet solution in British and Finnish adults. Food Qual Pref 2017:62:128-136.

6 Running head: Responses to sweetness

7

8 Affective responses to sweet products and sweet solution in British and Finnish adults

9 Hely Tuorila ${ }^{a *}$, Kaisu Keskitalo-Vuokko ${ }^{\mathrm{a}, \mathrm{b}}$, Markus Perola $^{\mathrm{c}}$, Tim Spector $^{\mathrm{d}}$, Jaakko Kaprio ${ }^{\mathrm{b}, \mathrm{c}, \mathrm{e}}$

11 aDepartment of Food and Environmental Sciences, University of Helsinki, P. O. Box 66, FI-00014

12 University of Helsinki, Finland

13 bepartment of Public Health, University of Helsinki, Finland

14 'National Institute for Health and Welfare, Helsinki, Finland

15 'Department of Twin Research and Genetic Epidemiology, King's College London, St Thomas'

17 Hospital, London SE1 7EH, UK

18

19 eInstitute for Molecular Medicine FIMM, University of Helsinki, Finland

20

$21 *$ Correspondence:

22 Hely Tuorila, PhD, hely.tuorila@helsinki.fi

Muotoiltu: englanti (Yhdysvallat)

Kentän koodi muuttunut

Muotoiltu: englanti (Yhdysvallat)

Muotoiltu: englanti (Yhdysvallat) 
Abstract

Responses to sweetness are reported in two populations, one segmented by gender and age, and the other one by gender only. The strength of the association between liking for specific sweet foods and liking for an aqueous sucrose solution $(20 \% \mathrm{w} / \mathrm{v})$ is also tested, and health attitudes examined. British adults ( $n=1855$, age 17-82, mean 55 years, 90\% women) and Finnish young adults ( $n=1292$, age $20-25$, mean 22 years, 54\% women) rated their liking of ten sweet foods and beverages based on names of products, and completed questionnaires on Craving for Sweet Foods (CSF) and General Health Interest (GHI). One-half of Brits and a third of Finns rated liking and intensity of sucrose solution. In factor analysis, identical categories of liking for sweet products were formed in each population, one consisting of five processed sweets ("Goodies"), and the other of naturally sweet fruits and berries ("Fruits"). Sugared and sugar-free soft drinks and fruit juice loaded on the third factor. After age 50, British men scored higher than British women in CSF and liking for several sweet products; Finnish women scored higher than Finnish men in CSF and liking for most sweet products. GHI was positively associated with liking for Fruits and negatively with liking for sugared soft drinks. Sucrose solution was better liked by British men than women, with no gender difference in Finns. Liking for sucrose solution was only weakly associated with liking for sweet products based on product names. In two demographically different European populations, attraction to sweet gathered in similar product categories, but manifested differently at different ages and gender.

KEYWORDS: sweet, liking, craving, gender, age 
Tuorila et al

Responses to sweetness

\section{Introduction}

Abundant sugar intake is a health concern worldwide (WHO, 2015). High consumption of monoand disaccharides added to foods is associated with higher body weight, and high consumption of sugar-sweetened beverages is associated with overweight and obesity in children (Te Morenga, Mallard, \& Mann, 2013; Cox, Hendrie, \& Carty, 2016). High sugar intake is also associated with increased incidence of dental caries (Moynihan, \& Kelly, 2014).

The flip side of the concern is the deeply rooted position of sweetness in our biology and culture (Rozin, 1982). Inclination to enjoy sweetness is inherent and evolutionarily well founded due to energy and nutrients associated with it (Drewnowski, Mennella, Johnson, \& Bellisle, 2012). Technologies to refine sugar from canes and beets, to produce a great variety of fine-tuned commercial sweet products, have been generated to satisfy the indulgence for sweetness. Further technological development has introduced intense sweeteners to the market to satisfy the need without calorie load and caries risk (Spillane, 2006).

Data from Finnish families (Keskitalo et al., 2007a) and British and Finnish twins (Keskitalo et al., 2007b, 2008) suggest that part of the predilection for sweetness ("sweet tooth") is inherited and thus, it runs in families. Evidence for some genetic influence was also found in 3-year-old twins whose parents rated their preference for snacks that were primarily sweet (Fildes et al., 2014). Studying genetic variations in the perception of sweetness in children and adults, Mennella, Pepino, and Reed (2005) concluded that in adults, cultural forces override genetic effects. Thus, genetic architecture defines the basis on which the cultural supply of products builds individual profiles of sweet preferences and inclinations.

The data of the present study were originally collected for the purpose of research on genetics of sweetness preferences. We measured sweetness perception using a sweet aqueous solution of sucrose - a simple and universal stimulus which is easy to present to large populations (Keskitalo et al., 2007b, 2008). For getting a wider perspective to sweetness perceptions we developed a questionnaire in which liking responses to sweet products and craving for sweet foods were recorded from British and Finnish twins (Keskitalo et al., 2007b, 2008; Knaapila et al. 2011). These data were used in the search of genetic roots in sweetness preferences using a twin paradigm (Keskitalo et al, 2007b, 2008; Knaapila et al., 2011), and of specific trait locus of genetic linkage analysis (Keskitalo et al., 2007a). Because of the long term data collection expanding over years, 
Tuorila et al

Responses to sweetness

and the focus of the reports, only a part of the outcome data have been incorporated into the published papers.

The data contain unique and as yet unused information of the attraction to sweetness in two large, separate populations at three levels: 1 ) hedonic and intensity ratings of a simple aqueous solution of sucrose, 2) reported liking and use frequency of a range of everyday sweet foods and beverages, and 3) craving for sweet foods, measured by a six-item validated instrument (CSF)(Roininen, Lähteenmäki, \& Tuorila, 1999). Analyzing the data fills a gap in knowledge of general sweetness preferences, as the published literature tends to focus on specific sensory stimuli in specific experimental conditions (an exception is the large web-based study with French consumers, Urbano et al., 2016). The British respondents covered a wide age range, thus enabling the analysis of responses to sweetness across age groups. Both the British and Finnish data contained responses from both genders, thus gender differences could be analyzed. By reporting on two data sets that share the methodology in the same paper, we seek to identify characteristics of sweetness responses that are not bound to a specific age group, gender or cultural setting. The members of twin pairs are here treated as individuals, but their data are not statistically independent observations, which is taken into account in statistical analyses (see Section 2.3 Statistical analysis).

The data also allow to examine the prediction of liking for sweet products from responses to an aqueous sucrose solution, a stimulus that is widely and universally used in the measurement of sweetness attraction (e.g., Esses, \& Herman, 1984; Desor, \& Beauchamp, 1987; Mennella et al., 2005; Keskitalo et al., 2007a, 2007b, 2008; Mennella, Finkbeiner,\& Reed, 2012; Pepino, \& Mennella, 2012; Mennella, Finkbeiner, Lipchock, Hwang, \& Reed, 2014; Thai, Tan, Tan, Tey, Kaur, \& Say, 2011). The present analysis adds to research comparing liking for aqueous solutions with ratings of liking for sweet products based on their names (Kim, Prescott, \& Kim, 2014).

The General Health Interest (GHI) (Roininen et al., 1999) was used to examine the potentially controlling role of health attitudes in responses to sweetness. If powerful in this context, GHI should be negatively correlated with liking for sweet items that are perceived as unhealthful. Thus, the objective of the present study was to describe demographic variations in affective responses to a range of sweet foods and beverages in two populations of which one (British) allowed the examination of variation by gender and age, and the other (Finnish) by gender only. Besides ratings of liking of sweet products based on product names, also craving for sweet foods 
Tuorila et al

Responses to sweetness

(CSF) was measured. The secondary aim was to describe the demographic variations in responses to an aqueous sweet solution in the same populations and to examine the extent to which liking for the very sweet solution could predict the rated liking of sweet products based on product names. Finally, the capability of health attitude (GHI) to control the responses to sweetness was tested by correlational analysis.

2. Respondents and methods

\subsection{Respondents}

The present data were collected in British (UK) and Finnish twin research units in years 2005-2007, British data in English and Finnish data in Finnish language. Table 1 presents the distribution of participants by gender and age group, as used in the subsequent analyses. For brevity, we refer to British respondents as Brits and the Finnish respondents as Finns.

The British respondents ( $\mathrm{n}=1855$ individuals) were twins in the UK Adult Twin Registry (Spector \& Williams, 2006). A minority ( $n=188,10.1 \%)$ were men. The age range of the respondents was $17-$ 82 y (mean \pm SD: $54.9 \pm 12.7$; for men $54.9 \pm 14.1$, for women $54.9 \pm 12.6$ ). The present study was approved by the Guy's and St Thomas's Hospital Ethics Committee.

The Finnish data ( $n=1292$ individuals) were collected during the fourth wave assessment of the FinnTwin12 study (Kaprio, Pulkkinen, \& Rose, 2002), which is based on five consecutive and complete year cohorts of Finnish twins born in 1983-87. Close to half ( $n=594,46.0 \%)$ were men, and the age range was $20-25$ y (mean \pm SD: $22.4 \pm 0.7$, for men and women identical). The present study was approved by the Coordinating Ethics Committee of Helsinki University Hospital and the IRB of Indiana University, Bloomington, IN.

Data on weight and height were available from 98.3\% $(n=1823)$ of the British and $99.0 \%(n=1279)$ of Finnish respondents. Of the Brits, $44 \%$ were normal-weight (BMI $\leq 25), 36 \%$ overweight (BMI > $25 \ldots 30)$, and $20 \%$ obese $(\mathrm{BMI}>30)$. The corresponding figures for the young adult Finns were $75 \%$, $20 \%$, and $5 \%$.

\subsection{In person testing procedure}

The respondents visited the clinic after overnight fasting, and rated the sweet aqueous solution of sucrose $(20 \% \mathrm{w} / \mathrm{v})$ as described by Keskitalo et al. (2007b). This concentration of sucrose was chosen as it yielded highest heritability estimates and best differentiated between respondents. 
Tuorila et al

Responses to sweetness

Thus it was expected to best reflect the underlying preference for sweet taste in Keskitalo et al. (2007a) study, in which also lower sucrose concentrations were rated. After rinsing their mouths with tap water, the respondents received the solution $(20 \mathrm{~mL})$ at room temperature. They were instructed to take it into the mouth and swirl around 5-10 s, and expectorate. The degree of liking was then rated using a $120 \mathrm{~mm}$ Labeled Affective Magnitude scale (LAM) (Schutz \& Cardello, 2001) and the intensity using $120 \mathrm{~mm}$ Labeled Magnitude Scale (LMS) (Green et al., 1996). The verbal anchors of LAM scale ranged from "greatest imaginable dislike" (- 60) to "greatest imaginable like" $(+60)$, with "like slightly" at +5 (dislike -5), "like moderately" at +20 (dislike -20) and "like very much" at +32 (dislike -32). The verbal anchors of LMS scale were at +2 ("barely detectable"), +5 ("weak"), +19 ("moderate"), +40 ("strong"), +60 ("very strong"), and +120 ("strongest imaginable sensation"). Of the Brits, 53\% ( $n=987)$ and of the Finns, 36\% ( $n=468)$ participated in the sensory rating task (see Table 1). The partial attendance in the tasting session was due to procedures: in the UK, the questionnaires were filled out from the year 2005 to 2007, but the collection of sensory data was finished earlier (in 2006); and the participation in the sensory test was not requested of diabetics. In Finland, part of the participants did not visit the clinic and thus did not rate the solution, but completed the questionnaire at home and then mailed it to the clinic.

The respondents completed an extensive questionnaire prior to visiting the clinic. In the questionnaire, also aspects of their preferences and use of sweet items were queried. They rated their degree of liking for 34 (British) or 38 (Finnish) sweet or non-sweet foods and eight sweet or non-sweet beverages. Ten of these were sweet items to which the present study focuses: five (chocolate, ice cream, sweet desserts, sweet pastry, and other sweets "candy") were solid, typically sugar-sweetened processed products; three were sweet beverages (fruit juice; sugared soft drinks; "unsugared" (British questionnaire) or "sugar-free" (Finnish questionnaire) soft drinks, in the present text they are called sugar-free); and two were naturally sweet solid products (fruits and berries). The foods and beverages were rated from $1=$ dislike very much to $7=$ like very much (British) or 1 = very unpleasant to 7 = very pleasant (Finnish), thus the value 4 equaled neutral. The Finnish language lacks the word "dislike", and to allow bipolar evaluations, pleasantness was rated by Finns instead of ratings of liking (for the comparison and use of scales anchored by pleasantness and liking, see Tuorila et al., 2008). In the following, the ratings will be referred to as liking. Use frequencies of the same foods were rated from $1=$ never to $6=$ several times a day (see Keskitalo et al. 2007b), but due to our focus on hedonics and to relatively high positive 
Tuorila et al

Responses to sweetness

correlations with ratings of liking of the ten products $(r=0.50-0.68$, Brits; and $r=0.35-0.58$, Finns), the use frequency data will not be reported in detail.

Two subscales of internationally validated (Roininen et al., 2001) Health and Taste Attitude Scales (Roininen et al., 1999) were completed: six statements quantifying Craving for Sweet Foods (CSF), and eight statements quantifying the General Health Interest (GHI). Rated statements for CSF were, for example: "I often have cravings for sweets" (positive) and "In my opinion it is strange that some people have cravings for chocolate (negative). Rated statements for GHI were, for example: "I am very particular about the healthiness of food I eat" (positive), and "I eat what I like and I do not worry much about the healthiness of food" (negative). Statements were rated from 1 = strongly disagree to 7 = strongly agree.

2.3 Statistical analysis

The British and Finnish data were analyzed separately. Data analysis was conducted using SPSS statistical software, version 21 (SPSS Inc., Chicago, IL) and Stata version 13 (Stata Corp, College Station, TX).

Correlations between ratings of sweetness and responses to sweet products were computed as the Pearson's product moment coefficients. Factor analysis was applied to find groupings of liking responses to ten sweet products.

CSF and GHI were constructed as described by Roininen et al. $(1999,2001)$. Thus, after reversal of ratings of statements that were negative to the target, individual means were calculated to indicate the strength of GHI (alpha $=0.77$, Brits, and 0.90, Finns) and CSF (alpha $=0.70$, Brits, and 0.84 , Finns). Both subscales could theoretically range from 1 to 7 .

One-way analysis of variance was used to reveal gender differences in ratings of liking in each population, and age differences in liking and intensity of sucrose solution in the British respondents. Two-way analysis of variance was used to examine the effects of age and gender and their interactions, on ratings of liking in the British respondents. Post hoc comparisons of liking and intensity ratings of the sweet solution in different age groups were conducted with Tukey test.

The effect of the design (ratings from twin pairs) was taken into account by using statistical models for complex survey data. The twins have been sampled as pairs and so the individual twins are not 
Tuorila et al

Responses to sweetness

statistically independent observations. The "svy" option or cluster-correction in Stata was used to derive proper standard errors and p-values (Williams, 2000).

Statistically significant $(p<0.05)$ values are reported below.

3. Results

3.1 Categories of sweet products and responses to sweetness

Factor analysis on ratings of liking for 10 sweet products resulted in similar structures in British and Finnish data (Table 2). Five semi-solid and solid sweet products (desserts, pastry, sweets, chocolate, ice cream, called by a common name "Goodies") loaded strongest on the first factor (variations explained 31 and 33\%). Liking for Goodie scale formed based on this factor had Cronbach's alpha $=0.85$ and 0.88 , for Brits and Finns, respectively. Naturally sweet products (fruits and berries, called by a common name "Fruits") loaded on the second factor ( $18 \%$ of variation explained in both data sets). The corresponding liking for Fruits scale had alpha 0.76 in Brits and 0.82 in Finns. Liking for beverages loaded mainly on the third factor (16\% in both data sets), but their mutual associations were low for which reason no common group was formed. The subsequent analyses were mainly (apart from the final correlations) conducted on each individual product to preserve the product-specific information unique in the present data. However, it is noteworthy that the two demographically different European populations rated their liking for 10 sweet items in a way that resulted in similar factor structures and almost identical proportions of variation explained.

Factor analysis on use frequencies of sweet products followed the patterns observed for liking data, confirming the close association of liking and reported use.

\subsection{Gender and age associations of responses to sweetness}

Sweet products were generally well-liked: except for the sugared soft drinks in the British respondents, mean ratings were well above the neutral (value 4) for both populations and all products (Figure 1). British men rated ice cream and sugared soft drinks higher $(p<0.001)$, but fruits $(p=0.005)$ and berries $(p=0.002)$ lower than did women. Among British respondents, no gender differences were seen for the remaining six sweet products (chocolate, sweet desserts, sweet pastry, sweets, sugar-free soft drinks and fruit juice) (Figure 1A). Finnish men rated sugared soft drinks $(p<0.001)$ and fruit juice $(p=0.007)$ higher, but rated the remaining eight sweet items lower than women (Figure 1B). 
In Figure 2, the mean ratings of products by age groups in Brits are shown for genders separately. Given the limited age variability among Finns, the analysis of age effects was not meaningful. Significant U-shaped main effects of age were observed for sweet desserts and for sweet pastry (Figure 2C and 2D), with the youngest and oldest age groups rating them highest $(F[4,953]=6.0$, $p<0.001$ for desserts and 5.0, $p=0.005$ for pastry). An age effect was also found for soft drinks (Figure 2F and 2G) such that older participants had lower liking ratings $(F[4,950]=15.9, p<$ 0.001 for sugared and $8.3, p<0.001$ for sugar-free soft drinks). Older subjects reported higher liking of fruits and berries (Figure $2 \mathrm{I}$ and $2 \mathrm{~J})(\mathrm{F}[4,953]=3.4, \mathrm{p}=0.01$ for fruits and 5.8, $p<0.001$, for berries).

Two significant age by gender interactions were found. With increasing age, ratings of chocolate (Figure 2A) and sweets (Figure 2E) were higher for men, but lower for women $(\mathrm{F}[4,1732]=4.1, \mathrm{p}$ $=0.0013$ for chocolate and 2.9, $p=0.023$ for sweets). A similar tendency for interaction was observed for the remaining processed sweets.

Mean craving (CSF) was higher in Finnish women than in Finnish men (mean ratings 4.7 and 3.6, respectively, $F[1,1290]=209, p<0.001$ ). In the British data, CFS varied by gender and age (Figure 3). On average, the British women scored higher for craving than men (mean values 4.2 and 3.9, respectively) $(F[1,1845]=8.3, p=0.004)$, but a significant gender by age interaction $(F[4,1845]=$ $5.0, p=0.001$ ) indicated that craving was less in older women, but greater in older men.

Mean health interest (GHI) was higher in British women (mean 5.1, SD 1.1) than in men (mean 4.6, SD 1.2). The corresponding mean for the Finnish women was 4.5 (SD 1.3) and for men 3.7 (SD 1.3). To provide a context for the ratings of liking of sweet foods, we computed mean ratings of nonsweet products (Table 3), including those 26 foods and beverages that, in the questionnaires, were identically defined to Brits and Finns (e.g., some fish dishes and cereals were defined in culture specific ways and therefore excluded). The mean ratings of 26 foods were 5.2 (Brits) and 5.4 (Finns), suggesting on average fairly positive and similar ratings of food likes/dislikes in both countries. With the exception of sugared and sugar-free soft drinks, the sweet products were rated higher than these averages, supporting the notion that sweetness plays an important role in making products attractive.

3.3 Responses to the aqueous sucrose solution and their relationship to other ratings 
Tuorila et al

Responses to sweetness

In both populations, mean hedonic ratings of the sweet solution were above neutral, although on average much below the verbal anchor "like moderately" (Figure 4). British men rated their liking higher than did British women $(F[1,508]=6.3, p=0.012)$, whereas no gender difference was observed between Finnish men and women. Hedonic ratings varied widely, from -60 to +54 in Brits and from -44 to +55 in Finns. The share of non-likers of sweet solution (ratings below 0 ) was $42.1 \%$ and $24.4 \%$ in Brits and Finns, respectively. Both genders rated the intensity of sweetness similarly in both countries. Brits had higher ratings of liking after age 50 years. This finding is however tempered by the fact that intensity ratings decreased with increasing age (Table 4).

Correlations between sweetness related measurements are presented in Table 5. In both populations, liking for the sweet sucrose solution was significantly, but weakly, related to liking for Goodies and sugared soft drinks; in Brits, it was very weakly related to craving (CSF). CSF was strongly associated with liking for Goodies and significantly also with other sweet items. GHI was positively related to liking for Fruits and negatively to liking for sugared soft drinks.

\section{Discussion}

The two demographically different populations, Brits and Finns, rated their liking (and also frequency of use) of 10 sweet items such that in factor analyses, similar factor structures and identical proportions of explained variation emerged from the analyses. This implies that in spite of different food cultures, major categories of sweet foods are similar in the minds of these respondents representing two European food cultures. In more detailed scrutiny including the variations by gender and age, responses to sweetness at the three levels of measurement (liking of sweet foods based on food name, craving, and ratings of aqueous sucrose solution) show a more complex picture of sweetness preferences.

\subsection{Gender, age and sweetness}

Gender differences in liking for sweet foods, based on food names, were only a few in the Brits, but clear and consistent in the young adult Finns: Finnish women scored higher than men for all sweet items except sugared soft drinks and fruit juices. Note however that the British age group 17-39 years (closest to the age of Finnish respondents, 20-25 years), was similar to the Finns in that women rated chocolate, sweets and fruits higher than men, and men rated the sugared soft drinks higher than women. Contrary to the young adult Finns, the youngest British adult men and women did not differ in their responses to ice cream, sweet desserts, and sweet pastry. Early 
Tuorila et al

Responses to sweetness

literature on young adult Finns $(n=224)$ found that posed to food names, Finnish women rated sweet foods higher than men did (Tuorila-Ollikainen, \& Mahlamäki-Kultanen, 1985). This corresponds to the present results with young Finnish adults and, partly, younger Brits. We could tentatively conclude that gender differences in sweet product preferences are seen clearly in young adulthood and diminish or disappear when people get older.

However, the present British data suggest that, when men grow older ( $>50$ years), their attachment to sweetness grows (displayed by heightened CSF) and they show heightened liking for processed sweet foods. Such gender by age interaction in responses to sweetness has not been reported earlier. It could either mean that for a physiological, psychological or psychosocial reason, men develop heightened liking for sweetness in older age, or it may possibly derive from a specific cohort effect. In the large web-based survey ( $>40000)$, French men rated their liking for sweet foods, added sugar, and natural sweetness higher than women did (Deglaire et al., 2015), but both genders showed decreased liking for sweetness with older age (Lampure et al., 2015). In their literature review, Issanchou and Nicklaus (2006) conclude that men, compared to women, generally seem to prefer sweetness. The present gender by age interaction suggests a somewhat more complex view.

In a cross-national data (Roininen et al., 2001), gender had a main effect on craving for sweet such that Finnish and British women rated higher than Finnish and British men in CSF; that study did not analyze the effect of age nor the gender by age interaction on CSF. The lower values of CSF at older age were observed in a Finnish representative cross-sectional data (Roininen et al., 1999). The extent to which craving for sweet (intense desire, see e.g., Pelchat, 1997) parallels or merges liking for sweet can be questioned. However, the composite six-item instrument CSF used in the operationalization of craving appears to capture liking for sweet items, as demonstrated by relatively high correlations ( 0.44 for Brits, 0.52 for Finns) between CSF and liking for Goodies.

Culture was suggested as a possible explanation for differences in Japanese and Australian responses to sweetness (Laing et al., 1994). Likewise there are major cultural, historical and societal differences between European countries in the role and position of foods and meals (Meiselman, 2009). For example, sweet confectionery has long been an intimate part of the British food culture (James, 1990), while the Finnish food culture is rather characterized by powerful nutrition policies (Prättälä, 2003). We may speculate that such differences affect the exposure and attitudes towards sweet foods in gender specific ways. At this point of time and available 
Tuorila et al

Responses to sweetness

information from two European populations, we conclude that inclination to like sweetness or sweet items is not strongly tied to biological sex or cultural gender. Rather, preference for sweet may vary due to a complex interplay between inputs from biology and culture. Biology includes factors such as genetics ("sweet tooth") and physiological state, and culture includes e.g., availability of sweet items, affluence of society, and parenting practices.

Naturally sweet products (fruits, berries, and fruit juice) were highly liked by all respondents. In both populations, women liked fruits and berries more than men did. Liking for fruits and berries was unrelated to liking for sweet solution, and rather weakly associated with CSF (the association was found in the Finnish data only). Furthermore, in the factor analysis naturally sweet items formed their own, separated factor. Although sweet, fruits may not primarily be considered as sweet items, or they form their own specific sub-category among sweet items. This view is supported by the British analysis of responses to sweetness (Conner, \& Booth, 1988), in which factor scores of liking for sweet snacks were not correlated with those of liking for sweet vegetables and fruit. Sweet fruits and vegetables are preferred foods for most primates (Beauchamp, 2016), while industrially processed sweet foods are a very recent development and hence the attraction to them is bound to be more culturally dependent.

British men rated their liking for aqueous sucrose solution higher than British women. No gender differences in the corresponding ratings were observed in the Finns. Liking of the aqueous sweet solution increased with age, but was accompanied by decreased perception of sweetness intensity. A similar trend was found when elderly subjects rated orange drinks containing 8 to 23.5\% sucrose (Zandstra, \& De Graaf, 1998). In the course of age, Malaysian respondents rated both the intensity and pleasantness of cola drinks lower (Thai et al., 2011). Decreasing sweetness preference from the teenage to the adult age has been shown in a longitudinal study (Desor, \& Beauchamp, 1987), and 6-10-year old children preferred higher sweetness than their mothers (Mennella et al., 2005). An earlier British study with an age range from childhood to 67 years (Conner, \& Booth, 1988) suggested less liking for a sweet drink the older the respondent; that study did not examine gender by age effects. Taken together, sweetness in simple solutions (water or beverage) attracts teenagers and younger more than adults, but sweetness may again be attractive in older age, if the intensity is perceived weaker. Desor and Beauchamp (1987) propose that this makes sense evolutionarily, as adolescents and young adults need energy for growth and reproduction. 
Tuorila et al

Responses to sweetness

4.2 Do ratings of an aqueous sucrose solution predict liking for sweet foods?

Ratings of liking for the $20 \%$ aqueous solution of sucrose were only weakly correlated with liking (based on product names) for Goodies and sugared soft drinks in both populations ( $r=0.13-$ 0.19). Among the Finns, they were also correlated with liking for juice, but again very weakly ( $r=$ $0.10)$. Although traditionally used in the measurement of sweetness preference (e.g., Esses, \& Herman, 1984; Desor, \& Beauchamp, 1987; Mennella et al., 2005; Pepino, \& Mennella, 2012; Keskitalo et al., 2007a, 2008) and successfully used as a component of such measurements (Keskitalo et al., 2007b), the aqueous sucrose solutions do not appear to be adequate surrogates for sweet products in studies aiming to broadly define "sweet tooth". Even when two sets of sensory stimuli, water solution and jellies, were compared for the most preferred concentration of sucrose, the correlation was only $r=0.19$ (Mennella et al. 2014), and in case of water and pudding, correlation was in adults $r=0.23$ (Mennella et al., 2012). The advantage of sugar solutions, compared to specific sweet foods and beverages, is their relative independence from the cultural context which shapes preferences by repeated exposures to sweet foods (Rozin, 1982; Laing et al., 1994; Prescott et al., 1997).

In a recent study, respondents tasted sucrose solutions and beverages and were clustered based on hedonic rating patterns (Kim et al., 2014). In a cluster of respondents that particularly favored high sweetness, ratings of the aqueous sweet solutions closely corresponded ratings of flavored beverages; in two other clusters the associations were less clear (Kim et al., 2014). Furthermore, these authors found only a few associations between each cluster and rated liking of sweet products based on product names. Within the realm of sweetness there is a wide range of different and unique products that appear to evoke consumer responses that are specific to each product.

\subsection{General Health Interest as a gatekeeper}

GHI acted similarly in British and Finnish populations, being positively correlated with liking for fruits and berries and negatively correlated with liking for sugared soft drinks. The correlations of GHI with liking for Goodies, juice and sugar-free soft drinks were none or negligible. Thus, only responses to products that have strong health-related connotations, positive (fruits) or negative (sugared soft drinks) (Roininen, Lähteenmäki, \& Tuorila, 2000), were influenced by GHI. In keeping with the theory on attitude activation (Fazio, Sanbonmatsu, Powell, \& Kardes, 1986), liking for products with weaker health connotations was not controlled by GHI. We conclude that health 
Tuorila et al

Responses to sweetness

attitudes, here quantified by $\mathrm{GHI}$, are capable of regulating the appeal to sweet products in modern consumers.

Acknowledgements

The design and data collection were supported by the Academy of Finland (grants 206327 and 108297) and the GenomeEUtwin Project (QLG2-CT-2002-01254). TwinsUK is funded by the Wellcome Trust, Medical Research Council, European Union, the National Institute for Health Research (NIHR)-funded BioResource, Clinical Research Facility and Biomedical Research Centre based at Guy's and St Thomas' NHS Foundation Trust in partnership with King's College London. The Finnish Twin Cohort has been supported by ENGAGE - European Network for Genetic and Genomic Epidemiology, FP7-HEALTH-F4-2007, the Academy of Finland Center of Excellence in Complex Disease Genetics (grant numbers: 213506, 129680), and the Academy of Finland (grants 265240, 263278). Data collection of the FinnTwin12 sample has been supported by the national Institute of Alcohol Abuse and Alcoholism (grants AA-12502, AA-00145, and AA-09203 to R J Rose), and by the Academy of Finland (grants 100499, 205585, 118555, 141054 and 264146 to JK).

\section{References}

Beauchamp, G.K. (2016). Why do we like sweet taste: A bitter tale? Physiology \& Behavior, 164, 432-437.

Conner, M.T., \& Booth, D.A. (1988). Preferred sweetness of a lime drink and preference for sweet over non-sweet foods, related to sex and reported age and body weight. Appetite, 10, 25-35.

Cox, D.N., Hendrie, G.A., \& Carty, D. (2016). Sensitivity, hedonics and preferences for basic tastes and fat amongst adults and children of differing weight status: A comprehensive review. Food Quality and Preference, 48, 359-367.

Deglaire, A., Méjean, C., Castetbon, K., Kesse-Guyot, E., Hercberg, S., \& Schlich, P. (2015) Associations between weight status and liking scores for sweet, salt and fat according to the gender in adults (The Nutrinet-Santé study). European Journal of Clinical Nutrition, 69, 40-46.

Desor, J.A., \& Beauchamp, G.K. (1987). Longitudinal changes in sweet preferences in humans. Physiology \& Behavior, 39, 639-641.

Drewnowski, A., Mennella, J.A., Johnson, S.L., \& Bellisle, F. (2012). Sweetness and food preference. Journal of Nutrition, 142, 1142S-1148S.

Esses, V.M., \& Herman, C.P. (1984). Palatability of sucrose before and after glucose ingestion in dieters and nondieters. Physiology \& Behavior, 32, 711-715. 
Fazio, R.H., Sanbonmatsu, D.M., Powell, M.C., \& Kardes, F.R. (1986). On the automatic activation of attitudes. Journal of Personality and Social Psychology, 50, 229-238.

Fildes, A., van Jaarsveld, C., Llewellyn, C. H., Fisher, A., Cook, K., \& Wardle, J. (2014). Nature and nurture in children's food preferences. American Journal of Clinical Nutrition, 99, 911-917.

Green, B.G., Dalton, P., Cowart, B., Shaffer, G., Rankin, K., \& Higgins, J. (1996). Evaluating the 'labeled magnitude scale' for measuring sensations of taste and smell. Chemical Senses, 21, 323334.

Issanchou, S., \& Nicklaus, S. (2006). Measuring consumers' perceptions of sweet taste. In: Spillane WJ (ed). Optimizing Sweet Taste in Foods. Woodhead, Cambridge, 97-131.

James, A. (1990).The good, the bad and the delicious: the role of confectionery in British society. Sociological Review, 38, 666-688.

Kaprio, J., Pulkkinen, L., \& Rose, R.J. (2002). Genetic and environmental factors in health-related behaviors: studies on Finnish twins and twin families. Twin Research, 5, 366-371.

Keskitalo, K., Knaapila, A., Kallela, M., Palotie, A., Wessman, M., Sammalisto, S., Peltonen, L., Tuorila, H., \& Perola, M. (2007a). Sweet taste preferences are partly genetically determined: identification of a trait locus on chromosome 16. American Journal of Clinical Nutrition, 86(1), 5563.

Keskitalo, K., Tuorila, H., Spector, T.D., Cherkas, L.F., Knaapila, A., Silventoinen, K., \& Perola, M. (2007b). Same genetic components underlie different measures of sweet taste preference. American Journal of Clinical Nutrition, 86, 1663-1669.

Keskitalo, K., Tuorila, H., Spector, T.D., Cherkas, L.F., Knaapila, A., Kaprio, J., Silventoinen, K., \& Perola M. (2008). The three-factor eating questionnaire, body mass index, and responses to sweet and salty fatty foods: a twin study of genetic and environmental associations. American Journal of Clinical Nutrition, 88, 263-271.

Kim, J.-Y., Prescott, J., \& Kim, K.-O. (2014). Patterns of sweet liking in sucrose solutions and beverages. Food Quality and Preference, 36, 96-103.

Knaapila, A., Silventoinen, K., Broms, U., Rose, R.J., Perola, M., Kaprio, J., \& Tuorila, H.M. (2011). Food neophobia in young adults: Genetic architecture and relation to personality, pleasantness and use frequency of foods, and body mass index - a twin study. Behavior Genetics, 41, 512-521.

Laing, D.G., Prescott, J., Bell, G.A., Gillmore, R., Allen, S., \& Best, D.J. (1994). Responses of Japanese and Australians to sweetness in the context of different foods. Journal of Sensory Studies, 9, 131135.

Lampuré, A., Schlich, P., Deglaire, A., Castetbon, K., Péneau, S., Hercberg, S., \& Méjean, C. (2015) Sociodemographic, psychological, and lifestyle characteristics are associated with a liking for salty and sweet tastes in French adults. Journal of Nutrition, 145, 587-594. 
Tuorila et al

Responses to sweetness

Meiselman, H.L. (ed.)(2009). Meals in science and practice. Interdisciplinary research and business applications. Cambridge: Woodhead.

Mennella, J.A,. Finkbeiner,S., Lipchock,S.V., Hwang, L-D., \& Reed, D.R. (2014). Preferences for salty and sweet tastes are elevated and related to each other during childhood. Plos One, 9(3), e92201.

Mennella, J.A., Finkbeiner, S., \& Reed,D.R. (2012). The proof is in the pudding: children prefer lower fat but higher sugar than do mothers. International Journal of Obesity, 36, 1285-1291.

Mennella, J.A., Pepino, M.Y., \& Reed, D.R. (2005). Genetic and environmental determinants of bitter perception and sweet preferences. Pediatrics, 115:e216-e222.

Moynihan, P.J., \& Kelly, S.A.M. (2014). Effect on caries of restricting sugars intake: systematic review to inform WHO guidelines. Journal of Dental Research, 93, 8-18.

Pelchat, M.L. (1997). Food cravings in young and elderly adults. Appetite, 28, 103-113.

Pepino, M.Y., \& Mennella, J.A. (2012). Habituation to the pleasure elicited by sweetness in lean and obese women. Appetite, 58. 800-805.

Prättälä, R. (2003).Dietary changes in Finland-success stories and future challenges. Appetite, 41, 245-249.

Prescott, J., Bell, G.A., Gillmore, R., Yoshida, M., O’Sullivan, M., Korac, S., Allen, S., \& Yamazaki, K. (1997). Cross-cultural comparisons of Japanese and Australian responses to manipulations of sweetness in foods. Food Quality and Preference, 8, 45-55.

Roininen, K., Lähteenmäki, L., \& Tuorila, H. (1999). Quantification of consumer attitudes to health and hedonic characteristics of foods. Appetite, 33, 71-88.

Roininen, K., Lähteenmäki. L., \& Tuorila, H. (2000). An application of means-end chain approach to consumers' orientation to health and hedonic characteristics of foods. Ecology of Food and Nutrition, 39, 61-81.

Roininen, K., Tuorila, H., Zandstra, E.H., De Graaf, C., Vehkalahti, K., Stubenitsky, K., \& Mela, D. (2001). Differences in health and taste attitudes and reported behavior among Finnish, Dutch and British consumers: A cross-cultural validation of health and taste attitude scales (HTAS). Appetite, 37, 33-45.

Rozin, P. (1982). Human food selection: the integration of biology, culture and individual experience. In Barker, L. M. (ed), The Psychobiology of Human Food Selection. Ellis Horwood: Chichester, 225-254.

Schutz, H.G., \& Cardello, A.V. (2001). A labeled affective magnitude (LAM) scale for assessing food liking/disliking. Journal of Sensory Studies, 16. 117-129.

Spector, T.D., \& Williams, F.M. (2006). The UK Adult Twin Registry. Twin Research and Human Genetics, 9, 899-906. 
Tuorila et al

Responses to sweetness

Spillane, W.J. (ed). (2006). Optimising Sweet Taste in Foods. Woodhead: Cambridge.

Te Morenga, L., Mallard, S., \& Mann, J. (2013). Dietary sugars and body weight: systematic review and meta-analyses of randomized controlled trials and cohort studies. British Medical Journal, 346, e7492.

Thai, P-K., Tan, E-C., Tan, W-L., Tey, T-H., Kaur, H., \& Say Y-H. (2011). Sweetness intensity perception and pleasantness ratings of sucrose, aspartame solutions and cola among multi-ethnic Malaysian subjects. Food Quality and Preference, 22, 281-289.

Tuorila, H., Huotilainen, A., Lähteenmäki, L., Ollila, S., Tuomi-Nurmi, S., \& Urala N. (2008). Comparison of affective rating scales and their relationship to variables reflecting food consumption. Food Quality and Preference, 19, 51-61.

Tuorila-Ollikainen, H., \& Mahlamäki-Kultanen, S. (1985). The relationship of attitudes and experiences of Finnish youths to their hedonic responses to sweetness in soft drinks. Appetite, 6 , 25-35.

Urbano, C., Deglaire, A., Cartier-Lange, E., Herbreteau, V., Cordelle, S., \& Schlich, P. (2016). Development of a sensory tool to assess overall liking for the fatty, salty and sweet sensations. Food Quality and Preference, 48, 23-32.

WHO (World Health Organization). (2015). Guideline: Sugars Intake for Adults and Children. Geneva: World Health Organization.

Williams, R.L. (2000). A note on robust variance estimation for cluster-correlated data. Biometrics, $56,645-646$.

Zandstra, E.H., \& De Graaf, C. (1998). Sensory perception and pleasantness of orange beverages from childhood to old age. Food Quality and Preference, 9, 3-12. 
Tuorila et al

Responses to sweetness

\section{FIGURE LEGENDS}

Figure 1. Mean $( \pm S D)$ liking for sweet products by A. British men and women $(n=188$ and 1667, respectively) and B. Finnish men and women ( $n=594$ and 698, respectively). Statistical difference between genders: $* * * p<0.001, * * p<0.01, * p<0.05$

Figure 2. Mean liking for sweet products by age group ( $x$-axis, 5 age groups) in British men and women ( $n=188$ and 1667, respectively). "M" refers to grand mean for each product. A. Chocolate, B. Ice cream, C. Sweet desserts, D. Sweet pastry, E. Sweets, F. Sugared soft drinks, G.

Unsugared/sugar-free soft drinks, H. Fruit juice, I. Fruits, J. Berries. SDs of individual data points varied from $0.8-2.2$.

Figure 3. Craving for Sweet Foods (means and SDs) by age group in British men ( $n=188)$ and women $(n=1667)$.

Figure 4. Liking $(A)$ and intensity $(B)$ ratings (mean $\pm S D$ ) of the sweet solution ( $20 \%$ sucrose) in British men ( $n=102)$ and women $(n=885)$, and in Finnish men $(n=186)$ and women $(n=282)$. LAM scale is shown from dislike very much (DVM) to like very much (LVM) with neutral (not like nor dislike $=L / D)$ in the center. LMS scale is shown from zero to very strong intensity ( $W=$ weak, $M=$ moderate, $S=$ strong, $V S=$ very strong). Ratings are presented as arithmetic means $( \pm S D)$. Statistical difference between genders: $* * p<0.01$. 


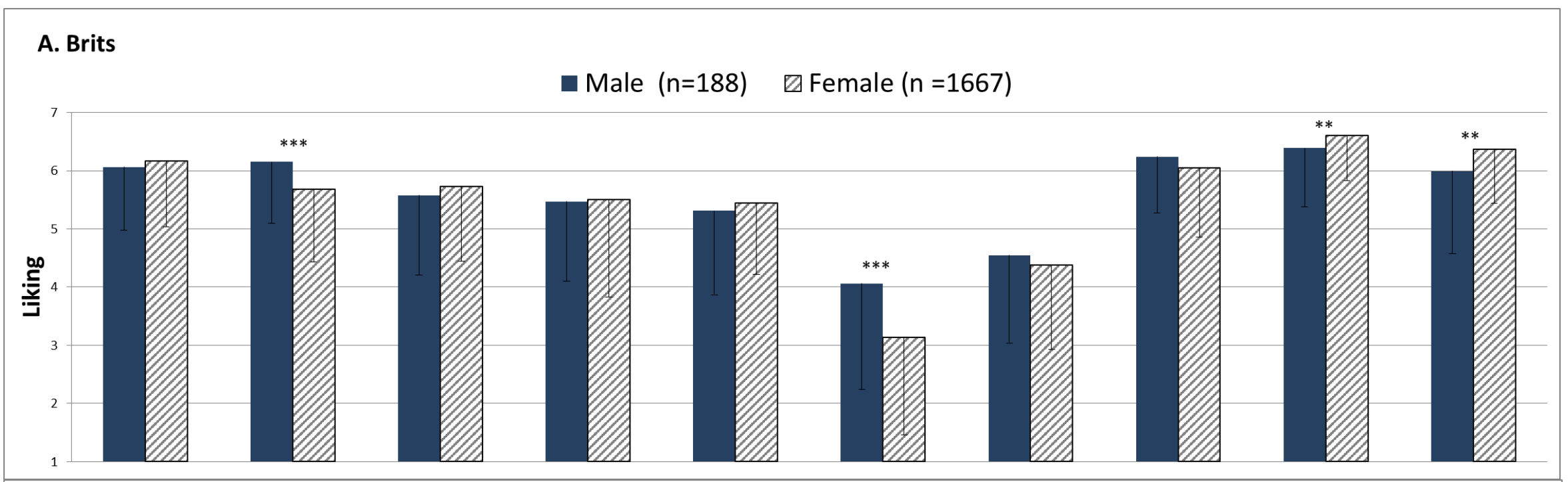

\section{B. Finns}




Figure 2
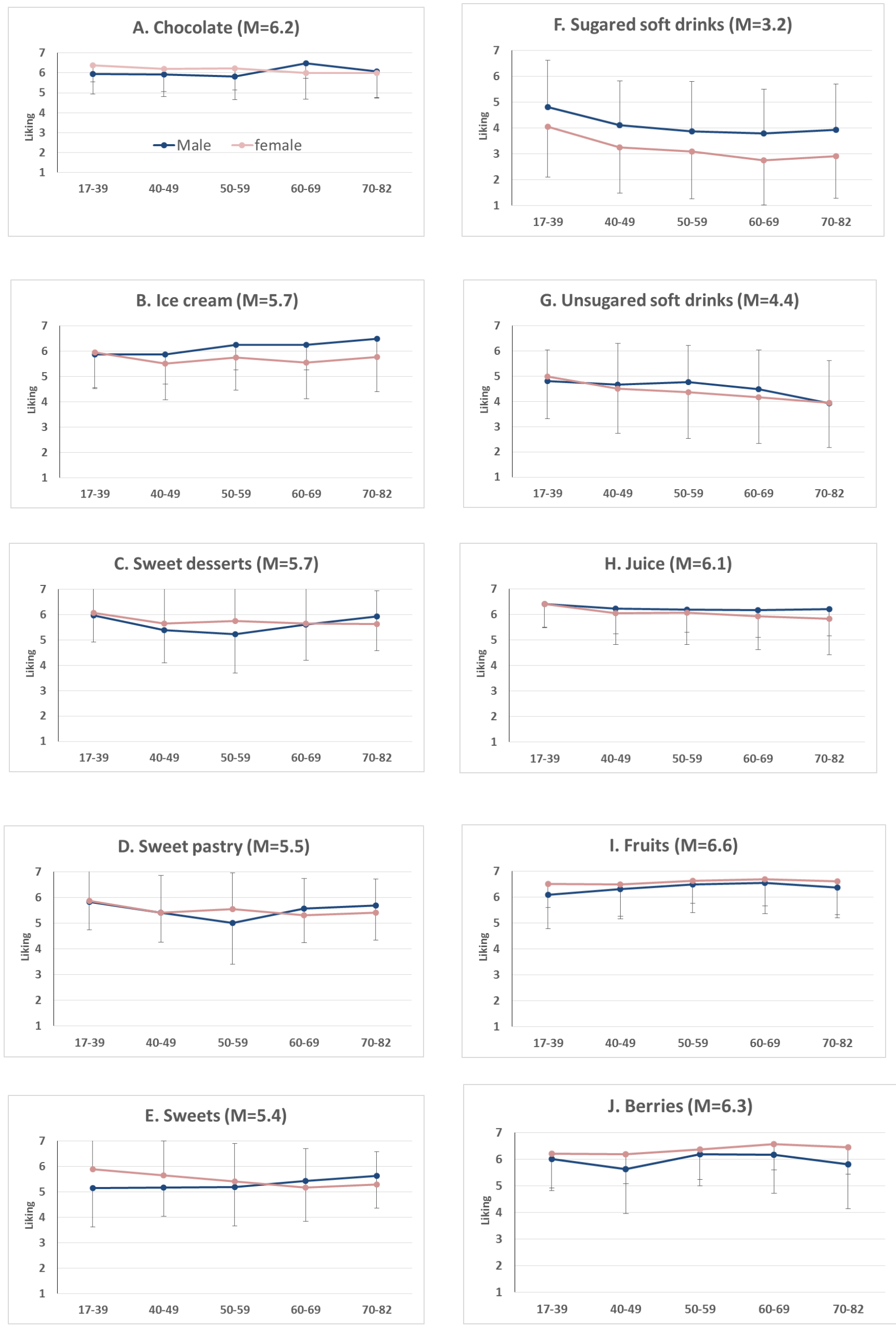
Figure 3

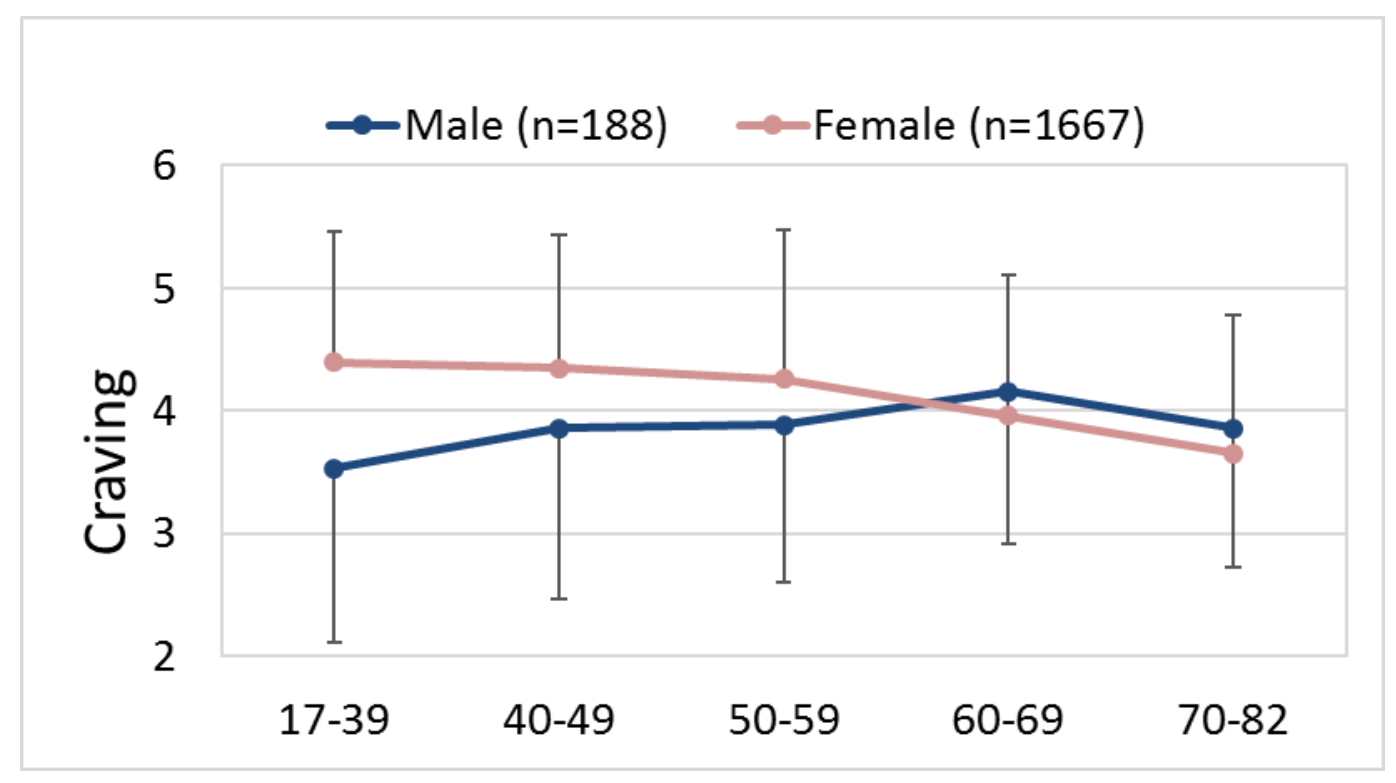



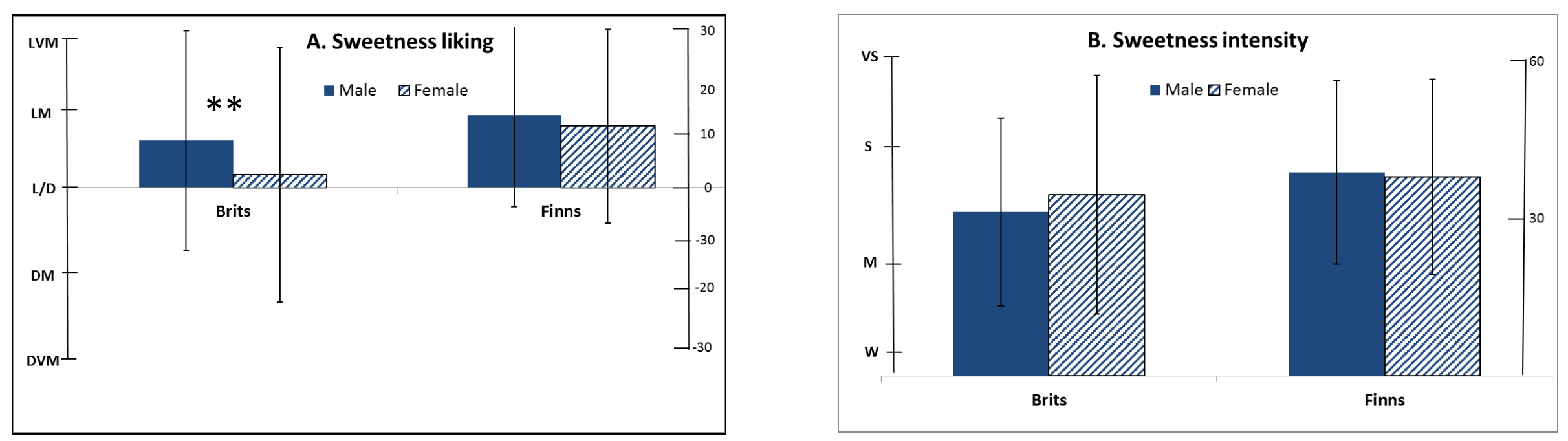
Table 1. Profiles of British and Finnish respondents. $M+F$ refers to the number of males + females.

\begin{tabular}{|c|c|c|c|c|c|}
\hline \multicolumn{2}{|l|}{ Background } & \multicolumn{2}{|l|}{ Brits } & \multicolumn{2}{|l|}{ Finns } \\
\hline Characteristic & Categories & $\begin{array}{l}\text { Questionnaire } \\
\mathrm{n}=1855(\mathrm{M}+\mathrm{F}) \\
(\%)\end{array}$ & $\begin{array}{l}\text { Subgroup } \\
\text { tasting sweet } \\
\text { solution } \\
\mathrm{n}=987(\mathrm{M}+\mathrm{F})\end{array}$ & $\begin{array}{l}\text { Questionnaire } \\
\mathrm{n}=1292\end{array}$ & $\begin{array}{l}\text { Subgroup tasting } \\
\text { sweet solution } \\
n=468\end{array}$ \\
\hline Sex & $\begin{array}{l}\text { Male } \\
\text { Female }\end{array}$ & $\begin{array}{l}188 \\
(10.1 \%) \\
1667 \\
(89.9 \%)\end{array}$ & $\begin{array}{l}102 \\
(10.3 \%) \\
885 \\
(89.7 \%)\end{array}$ & $\begin{array}{l}594 \\
(46.0 \%) \\
698 \\
(54.0 \%)\end{array}$ & $\begin{array}{l}186 \\
(39.7 \%) \\
282 \\
(60.3 \%)\end{array}$ \\
\hline $\begin{array}{l}\text { Age group } \\
\text { (years) }\end{array}$ & $\begin{array}{l}17-39 \\
40-49 \\
50-59 \\
60-69 \\
70-82\end{array}$ & $\begin{array}{l}242(33+209) \\
(13.0 \%) \\
306(29+277) \\
(16.5 \%) \\
623(49+574) \\
(33.6 \%) \\
501(45+456) \\
(38.6 \%) \\
183(32+151) \\
(9.9 \%)\end{array}$ & $\begin{array}{l}122(13+109) \\
(12.4 \%) \\
149(12+137) \\
(15.1 \%) \\
332(28+304) \\
(33.6 \%) \\
279(33+246) \\
(28.3 \%) \\
105(16+89) \\
(10.6 \%)\end{array}$ & $\begin{array}{l}1292 \\
(100 \%)\end{array}$ & $\begin{array}{l}468 \\
(100 \%)\end{array}$ \\
\hline
\end{tabular}


Table 2. Liking and use of sweet products grouped in factor analyses, varimax rotation, three factors F1 - F3; the variance of liking ratings explained at $65.2 \%$ in British ( $n=1855)$ and at $67.1 \%$ in Finnish $(n=1255)$ data, and variance of use frequency explained $53.4 \%$ in British and $53.6 \%$ in Finnish data. The sweet items within a factor are organized by the order of magnitude in loadings of liking in the British data. Values $>0.30$ marked as bold.

\begin{tabular}{|c|c|c|c|c|c|c|c|c|c|c|c|c|}
\hline \multirow[b]{3}{*}{ Factors } & \multicolumn{6}{|c|}{ Liking for products } & \multicolumn{6}{|c|}{ Use frequency of products } \\
\hline & \multicolumn{3}{|l|}{ Brits } & \multicolumn{3}{|l|}{ Finns } & \multicolumn{3}{|l|}{ Brits } & \multicolumn{3}{|c|}{ Finns } \\
\hline & F1 & F2 & F3 & F1 & $\mathrm{F} 2$ & F3 & F1 & F2 & F3 & F1 & F2 & F3 \\
\hline$\%$ variance explained & 31.2 & 17.9 & 16.0 & 32.9 & 17.9 & 16.3 & 23.7 & 15.7 & 14.0 & 25.6 & 14.0 & 13.9 \\
\hline Sweet desserts & 0.89 & 0.08 & 0.09 & 0.88 & 0.11 & 0.16 & 0.82 & 0.10 & 0.03 & 0.76 & 0.15 & 0.15 \\
\hline Sweet pastry & 0.84 & 0.07 & 0.09 & 0.88 & 0.09 & 0.14 & 0.74 & 0.08 & 0.02 & 0.77 & 0.09 & 0.09 \\
\hline Other sweets & 0.76 & -0.01 & 0.26 & 0.74 & 0.03 & 0.19 & 0.60 & -0.23 & 0.24 & 0.72 & 0.10 & -0.08 \\
\hline Chocolate & 0.75 & 0.06 & 0.02 & 0.76 & 0.10 & 0.08 & 0.65 & -0.12 & 0.02 & 0.71 & -0.01 & 0.01 \\
\hline Ice cream & 0.61 & 0.14 & 0.26 & 0.71 & 0.19 & 0.21 & 0.53 & 0.20 & 0.21 & 0.56 & 0.07 & 0.05 \\
\hline Berries & 0.07 & 0.88 & -0.00 & 0.18 & 0.89 & 0.01 & 0.03 & 0.80 & 0.01 & 0.14 & 0.06 & 0.77 \\
\hline Fruits & 0.10 & 0.88 & 0.04 & 0.12 & 0.90 & 0.11 & 0.01 & 0.79 & 0.03 & 0.01 & 0.06 & 0.76 \\
\hline Sugar-free soft drinks & 0.07 & 0.06 & 0.80 & 0.18 & 0.07 & 0.58 & 0.02 & -0.02 & 0.73 & 0.08 & 0.46 & 0.19 \\
\hline Sugared soft drinks & 0.29 & -0.22 & 0.70 & 0.23 & -0.21 & 0.76 & 0.29 & -0.31 & 0.60 & 0.21 & 0.68 & -0.37 \\
\hline Juice & 0.12 & 0.41 & 0.57 & 0.06 & 0.25 & 0.76 & 0.07 & 0.31 & 0.64 & 0.01 & 0.82 & 0.10 \\
\hline
\end{tabular}


Table 3. Mean (SD) ratings of liking for "other" (non-sweet) 26 foods rated by British ( $n=1855)$ and Finnish $(n=1292)$ respondents, listed according to descending mean rating of liking of Brits.

\begin{tabular}{|c|c|c|c|c|}
\hline \multirow[t]{2}{*}{ Product } & \multicolumn{2}{|c|}{$\begin{array}{l}\text { Brits } \\
(n=1855)\end{array}$} & \multicolumn{2}{|c|}{$\begin{array}{l}\text { Finns } \\
(n=1292)\end{array}$} \\
\hline & Mean & $S D$ & Mean & $S D$ \\
\hline Fresh vegetables & 6.6 & 0.8 & 5.9 & 1.2 \\
\hline Cooked vegetables & 6.6 & 0.9 & 5.2 & 1.6 \\
\hline Chicken or turkey & 6.4 & 1.2 & 6.2 & 1.7 \\
\hline Cooked or smashed potatoes & 6.1 & 1.2 & 6.2 & 1.8 \\
\hline Meat dishes & 6.1 & 1.4 & 6.2 & 2.6 \\
\hline Eggs & 6.0 & 2.1 & 5.5 & 1.9 \\
\hline Rice or pasta & 6.0 & 1.3 & 6.1 & 2.1 \\
\hline Tea & 5.9 & 1.7 & 5.2 & 1.6 \\
\hline Fried potatoes or French fries & 5.8 & 1.3 & 5.7 & 1.3 \\
\hline Yoghurt & 5.8 & 1.6 & 5.8 & 1.3 \\
\hline Semi-skimmed milk & 5.7 & 1.6 & 5.4 & 1.6 \\
\hline Salmon or rainbow trout & 5.6 & 1.9 & 5.9 & 1.6 \\
\hline Coffee & 5.4 & 1.8 & 5.2 & 2.0 \\
\hline Salty snacks & 5.4 & 1.5 & 5.9 & 1.2 \\
\hline Salad dressings & 5.1 & 1.6 & 5.0 & 1.5 \\
\hline Other cheeses & 5.1 & 2.0 & 5.9 & 1.9 \\
\hline Pizza & 5.0 & 1.6 & 6.2 & 1.0 \\
\hline Liquorice & 4.9 & 1.9 & 5.7 & 1.3 \\
\hline Creamy foods & 4.7 & 1.6 & 5.3 & 1.4 \\
\hline Reduced-fat cheeses & 4.4 & 1.7 & 5.1 & 1.5 \\
\hline Fried foods & 4.2 & 1.8 & 4.9 & 1.8 \\
\hline Skimmed milk & 4.1 & 2.1 & 5.6 & 1.7 \\
\hline Blue cheese & 4.0 & 2.4 & 4.2 & 3.4 \\
\hline Full fat milk & 3.7 & 2.2 & 3.5 & 1.9 \\
\hline Hamburgers & 3.7 & 1.9 & 5.8 & 1.3 \\
\hline Pickled herring & 2.8 & 2.1 & 3.1 & 2.2 \\
\hline Mean & 5.2 & 1.0 & 5.4 & 0.8 \\
\hline
\end{tabular}



Table 4. Ratings of liking and intensity of sweet solution by age groups in the British respondents, means and standard deviations (SD) are shown. Liking ratings (LAM scale) from -60 to $+60,-60=$ greatest imaginable dislike, $0=$ don't dislike nor like, $+60=$ greatest imaginable like; intensity ratings (LMS scale) from 0 to $120,60=$ very strong, $120=$ greatest imaginable sensation. Within a column, letters $a, b$, or $c$ shared by cells denote that values are not statistically different.

\begin{tabular}{|c|c|c|c|c|c|}
\hline \multirow{2}{*}{$\begin{array}{l}\text { Age group } \\
\text { (years) }\end{array}$} & \multirow[t]{2}{*}{$n$} & \multicolumn{2}{|l|}{ Liking } & \multicolumn{2}{|c|}{ Intensity } \\
\hline & & Mean & $S D$ & Mean & $S D$ \\
\hline $17-39$ & 121 & $3.1 a b$ & 25.9 & $41.4 a$ & 23.6 \\
\hline $40-49$ & 148 & $-2.6 a$ & 24.9 & $35.4 a b$ & 22.1 \\
\hline $50-59$ & 330 & $2.2 a b$ & 22.7 & 32.9abc & 22.0 \\
\hline $60-69$ & 278 & $4.9 \mathrm{~b}$ & 23.4 & $31.6 b c$ & 20.0 \\
\hline $70-82$ & 105 & $8.9 b$ & 20.6 & $28.1 c$ & 21.7 \\
\hline
\end{tabular}


Table 5. Correlations (Pearson's r) of responses to sweetness with a) liking for sucrose solution, b) Craving for Sweet Foods (CSF), and c) General Health interest (GHI) in British and Finnish respondents.

Values significant at $p<0.05, p<0.01$, and $p<0.001$ marked with $*{ }^{* *}$, and ${ }^{* * *}$, respectively.

\begin{tabular}{|c|c|c|c|c|c|c|}
\hline \multirow[t]{2}{*}{ Variable } & \multicolumn{2}{|c|}{ Liking for sucrose solution } & \multicolumn{2}{|c|}{ Craving for Sweet Foods } & \multicolumn{2}{|c|}{ General Health Interest } \\
\hline & $\begin{array}{l}\text { Brits } \\
(n=987)\end{array}$ & $\begin{array}{l}\text { Finns } \\
(n=468)\end{array}$ & $\begin{array}{l}\text { Brits } \\
(n=1855)\end{array}$ & $\begin{array}{l}\text { Finns } \\
(n=1292)\end{array}$ & $\begin{array}{l}\text { Brits } \\
(n=1855)\end{array}$ & $\begin{array}{l}\text { Finns } \\
(n=1292)\end{array}$ \\
\hline $\begin{array}{l}\text { Craving for Sweet } \\
\text { Foods }\end{array}$ & $0.07 *$ & 0.06 & & & & \\
\hline $\begin{array}{l}\text { General Health } \\
\text { Interest }\end{array}$ & -0.05 & -0.03 & 0.02 & $0.08 * *$ & & \\
\hline Goodies & $0.19 * * *$ & $0.13^{*}$ & $0.44 * * *$ & $0.52 * * *$ & -0.04 & 0.04 \\
\hline Fruits & 0.05 & 0.01 & 0.03 & $0.16 *$ & $0.29 * * *$ & $0.33 * * *$ \\
\hline Juice & 0.04 & $0.10 * *$ & $0.12 * *$ & $0.07 *$ & 0.03 & $-0.07 *$ \\
\hline $\begin{array}{l}\text { Sugared soft } \\
\text { drinks }\end{array}$ & $0.16^{* * *}$ & $0.15^{* *}$ & $0.13 * *$ & $0.09 * *$ & $-0.27 * * *$ & $-0.31 * * *$ \\
\hline $\begin{array}{l}\text { Sugar-free soft } \\
\text { drinks }\end{array}$ & 0.05 & 0.08 & $0.15^{* * *}$ & $0.16 * * *$ & 0.02 & $0.08^{*}$ \\
\hline
\end{tabular}

